\title{
Characterization of bovine respiratory syncytial virus isolated in Brazil
}

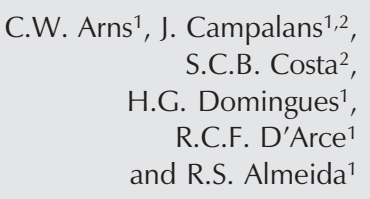

\author{
${ }^{1}$ Laboratório de Virologia Animal, Departamento de Microbiologia e Imunologia, \\ Instituto de Biologia, Universidade Estadual de Campinas, Campinas, SP, Brasil \\ ${ }^{2}$ Laboratório de Diagnóstico de Doenças Infecciosas por Técnicas de Biologia \\ Molecular, Departamento de Clínica Médica, Faculdade de Ciências Médicas, \\ Universidade Estadual de Campinas, Campinas, SP, Brasil
}

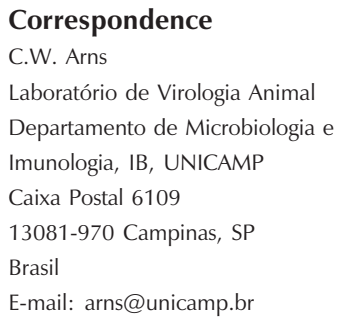

Received August 13, 2001 Accepted November 5, 2002

\begin{abstract}
This paper presents the first isolation of bovine respiratory syncytial virus in Brazil and its physicochemical, morphological and molecular characterization. The virus was isolated from 33 samples of nasotracheal secretions, successively inoculated into a Madin-Darby bovine kidney cell culture, which was characterized by physicochemical tests and morphological observation by electron microscopy. The Brazilian sample is an RNA pleomorphic, enveloped, thermolabile and nonhemagglutinating spicular virus. Reverse transcription, followed by nested polymerase chain reaction (nRT-PCR) assay was carried out using oligonucleotides B1, B2A, B3 and B4 for the fusion proteins (F) and B5A, B6A, B7A and B8 for the attachment protein (G). The nRTPCR-F amplified a fragment of $481 \mathrm{bp}$ corresponding to part of the gene that codes for protein F, whereas nRT-PCR-G amplified a fragment of $371 \mathrm{bp}$, in agreement with part of the $\mathrm{G}$ gene. The virus isolated from Brazilian samples in this study corresponded to the bovine respiratory syncytial virus, and RT-PCR proved to be useful for the diagnosis of bovine clinical samples.
\end{abstract}

Bovine respiratory syncytial virus (BRSV) is an important pathogen that causes acute respiratory distress syndrome, and has been detected in cattle since 1970 (1). BRSV is a single-stranded negative-sense RNA virus which belongs to the Pneumovirus genus, a member of the Paramyxoviridae family. Its genome has approximately 15,140 nucleotides and encodes 10 different mRNA molecules $(2,3)$. BRSV infection commonly occurs in cattle and serological studies indicate that the virus has already infected more than $95 \%$ of Brazilian cattle up to 3 years old, with $70 \%$ of the calves being infected within the first year of life (4). The mortality rate in some herds with confirmed acute infection ranges from 5 to $20 \%$ (5). This disease poses a serious problem due to financial losses caused by animal death, costs of treatment, and subsequent reduced profits.

Very little is known about the significance of BRSV in Brazil. Recent studies have demonstrated the presence of BRSV antibodies in numerous serum samples, as well as viral antigens in histological specimens used for the diagnosis of bovine infec- 
tions in the south and southeast regions of the country (6-9). A serological investigation was performed with 864 serum samples from 65 different farms located in the southern Brazilian states, using serum neutralization test (SNT) and enzyme-linked immunosorbent assay (ELISA), and the clinical history was analyzed. Both tests showed high frequencies of positive BRSV (68 and 75\%, respectively). Due to the high frequency of seropositivity detected in previous studies, there is a need to obtain Brazilian BRSV isolates in order to carry out detailed studies.

The isolation of BRSV is not commonly used for diagnosis since tissue samples containing high concentrations of BRSV antigen do not often yield the virus in cell cultures. In most cases, BRSV is obtained during isolation procedures for viral pathogens rather than procedures specifically carried out for BRSV (10). The transport of clinical specimens from the field greatly reduces the sensitivity of virus isolation, but has a minimal effect on the results of ELISA and reverse transcription-polymerase chain reaction (RT-PCR). These methods therefore are more suitable for diagnostic applications than virus isolation (11).

The objectives of the present study were to isolate BRSV from nasal secretion samples of young calves from Brazilian herds with respiratory distress signs, to characterize the viral agent by electron microscopy and to determine its physicochemical and molecular features, and to develop nested RT-PCR (nRT-PCR) as a diagnostic method for BRSV in cell culture.

Viral isolates were obtained from samples of nasotracheal secretion from live animals in the southern and southeastern regions of Brazil. A total of 33 samples were analyzed (20 from Rio Grande do Sul State and 13 from São Paulo State). The study involved 23 Brazilian dairy cattle herds (25 to 120 animals) and 10 beef cattle herds (80 to 700 animals) kept under extensive management. The samples were collected from herds pre- senting positive serology and from animals with respiratory distress signs.

Two positive control BRSV strains, BRSV-88 from Germany and the American Type Culture Collection reference strain Lehmkuhl 375 from the United States were used for the nRT-PCR-G assay, and an avian pneumovirus (SHS-121-BR) of the same subfamily was used as negative control.

The material for viral isolation was taken with swabs and transferred to tubes containing sterile Eagle's minimum essential medium with $20 \%$ glycerin, $20 \%$ horse serum and $5 \%$ antibiotic. The nasal secretions were frozen-thawed, homogenized at 1:10 dilution and centrifuged, and the supernatant was filtered through a $0.2-\mu \mathrm{m}$ filter. This filtrate $(0.1 \mathrm{ml})$ was inoculated simultaneously into a continuous Madin-Darby bovine kidney (MDBK) cell layer on 24-well microplates (Corning, New York, NY, USA). Each plate contained a cell control and a positive control (viral samples of BRSV). After 5 days of incubation with no detection of cytopathogenic effects, blind passages were carried out up to the 20th cell passage.

The following tests were used to determine the physicochemical features of the isolated virus: sensitivity to chloroform, temperature and 5-iodine-2-deoxyuridine, $\mathrm{pH}$ stability, hemagglutination, and hemadsorption activity according to the methodology described by von Mayr et al. (12). For this purpose, a cell monolayer with $24 \mathrm{~h}$ of growth at $37^{\circ} \mathrm{C}$ was used in $96-$ well microplates (Corning).

The procedures for viral purification were those used by Gough and Collins (13). Purified viral particles were visualized by electron microscopy using the method of Barth (14). The fast treatment with $2 \%$ phosphotungstic acid was performed. The preparations were examined with a transmission electron microscope (Zeiss, EM model 900), magnified 77,500, 131,000, and 142,000 times, at the Center for Electron Microscopy, Institute of Biology, UNICAMP, Cam- 
pinas, SP, Brazil.

The oligonucleotides used for nRT-PCR amplification were those reported by Vilcek et al. (5) based on the sequences of the $F$ and $\mathrm{G}$ genes of the BRSV.

Total RNA was isolated from MDBK cell cultures infected with BRSV. Two days after infection, when the cytopathogenic effect reached approximately $20 \%$, and monolayers were scraped, centrifuged, and lysed with Trizol $^{\mathrm{TM}}$ (Invitrogen, Carlsbad, CA, USA).

Reverse transcription was performed with Superscript ${ }^{\mathrm{TM}}$ RNAse H Reverse Transcriptase (Invitrogen) in a final volume of $20 \mu \mathrm{l}$ following the manufacturer's instructions.

Nested PCR was performed in a volume of $50 \mu \mathrm{l}$ including $4 \mu \mathrm{l}$ cDNA, containing $1 \mu \mathrm{l}$ 10 pmol of each primer, $5 \mu \mathrm{l} 10 \mathrm{X}$ RT-PCR buffer (200 mM Tris-HCl, pH 8.4, $500 \mathrm{mM}$ $\mathrm{KCl}), 2 \mu 150 \mathrm{mM} \mathrm{MgCl} 2,2 \mu 15 \mathrm{mM}$ deoxynucleotide triphosphate mix, $0.3 \mu 1$ Taq DNA polymerase (Invitrogen), and $34.7 \mu \mathrm{l}$ of diethyl pyrocarbonate-treated distilled water. RT-PCR was performed in a thermal cycler (PTC-100, MJ Research, Waltham, MA, USA).

Amplified DNA was visualized by $1 \%$ ethidium bromide staining in UV light, after $1.8 \%$ agarose gel electrophoresis at $90 \mathrm{~V}$ for 30 min and documented with an instant camera (Polaroid DS 34).

One of 33 cases examined was BRSV positive after viral isolation. The isolated BRSV sample was taken from a 2-month-old Holstein calf from the State of Rio Grande do Sul, located close to Argentina and Uruguay. Cough, nasal secretion and severe dyspnea were observed. This sample was packed in dry ice and arrived at the laboratory $18 \mathrm{~h}$ later. Successful isolation was obtained in MDBK cell culture after nine blind passages, with a perceptible cytopathic effectlike syncytial arrangement observed on the fourth day after inoculation. This viral sample, propagated and submitted to viral characterization tests, was named BRSV-
25-BR.

The isolation of BRSV is a laborious procedure with unpredictable results because animals that develop the disease are not the best choice for virus isolation. Tissue samples containing high concentrations of BRSV antigen frequently do not reproduce the virus in cell cultures (10). Several factors are involved, mainly high virus lability, which requires special care from the harvesting of samples to the inoculation in cell cultures. The time elapsed between the two phases must be minimal, and the virus should be kept at low temperatures. Another difficulty is the large number of cellular passages needed to obtain a successful isolation. Although BRSV may be present in many samples, isolation is not easily achieved, probably because the cell lines have few receptors for virus absorption.

Several clinical samples from the same source were tested for viral isolation and submitted to the same laboratory procedures, but it was not possible to isolate the virus from all of them. The distance from the laboratory and the transportation conditions, as well as sample packaging must have had an influence on the low yield of viral isolation.

It may be argued that successful isolation was favored by the use of live animal samples, which contained enough viral particles with infecting capacity in their cells. In former studies with samples from autopsied animal tissues, the difficulty in obtaining these free and infective viruses seemed to be greater due to the time elapsed between death, autopsy and inoculation in the cell cultures $(6,9)$. Furthermore, it is easier to obtain tissue samples from animals autopsied during the acute phase of the disease (10).

When physicochemical tests were performed with the isolated BRSV-25-BR samples, the 5-iodine-2-deoxyuridine treatment at the different concentrations analyzed $(0,10,50$ and $100 \mu \mathrm{g} / \mathrm{ml})$ showed that the infecting capacity of the virus was not 
affected, which is an indication that it is an RNA virus. Regarding temperature treatment, it was observed that exposure to $56^{\circ}$ and $60^{\circ} \mathrm{C}$ for a 30 -min period inactivated the viral sample. The same effect was observed regarding the chloroform effect. From the data obtained, it was possible to conclude that BRSV-25-BR is an enveloped virus, and the above procedures eliminated its infectivity.

The treatments at different $\mathrm{pH}$ values showed that the virus was stable over an extended $\mathrm{pH}$ range (6.0 to 9.0 ) at $4^{\circ} \mathrm{C}$, but was affected by exposure time at this temperature, especially after $180 \mathrm{~min}$. Cytopathogenic effects could not be detected at $\mathrm{pH} 3.0$ but there was a toxic effect on the cells.

The results of hemagglutination activity tests of the BRSV-25-BR sample using chicken, turkey, guinea pig, rabbit, mouse, bovine and sheep erythrocytes in $1 \% \mathrm{NaCl}$ buffer and incubation of 30 and $60 \mathrm{~min}$ at $4^{\circ} \mathrm{C}$ were negative. The same erythrocytes were used for the hemadsorption activity test. The viral incubation periods studied were 2,4 and $6 \mathrm{~h}$. The hemadsorption activity was negative. The results confirmed that this viral sample did not agglutinate or adsorb any kind of erythrocyte under investigation after the incubation periods tested.

The methods used for virus characterization, such as thermostability, chloroform sensitivity, $\mathrm{pH}$ stability, hemagglutination and hemadsorption tests, indicated that the sample can be identified as the bovine RNA virus, an enveloped non-hemagglutinant virus, with

Figure 1. Electron photomicrograph of BRSV-25-BR isolated from Brazilian samples. Negative staining $(\mathrm{bar}=100 \mathrm{~nm})$.

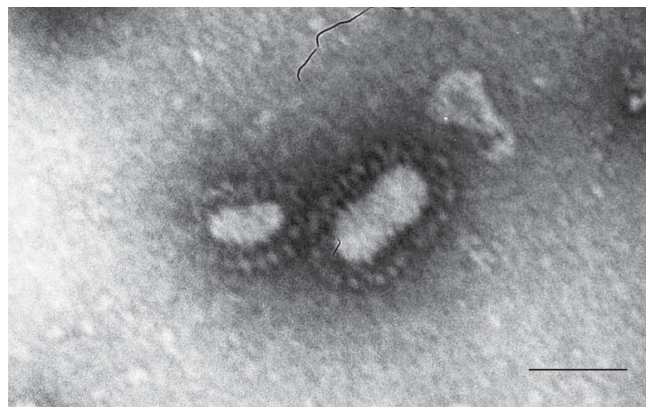

cytopathic effects characterized as syncytial formation. These are the characteristics of BRSV, which were described by Stott and Taylor (15) and Mallipeddi et al. (16).

BRSV-25-BR was studied morphologically by analysis of images generated by electron microscopy. The sample provided images of a pleomorphic virus, approximately 100-300 nm in size, showing the presence of spicules. A large number of defective or destroyed particles were observed, in agreement with data reported by Mallipeddi et al. (16). The images (Figure 1) showed the morphologic characteristics of BRSV and the physicochemical features allowed us to confirm that the virus isolated from cattle in Brazil is a strain of this virus.

RT-PCR has been extensively applied in modern microbiology for molecular analysis, although only a few laboratories use this technique as a routine clinical test. Nested RT-PCR assays are useful tools, showing high sensitivity and specificity for BRSV detection in clinical material, better than virus growth in cell culture $(11,17,18)$. Furthermore, comparative analysis revealed that nRT-PCR was ten times more sensitive than RT-PCR (5).

In the present study two nRT-PCR tests were developed based on the fusion protein gene (nRT-PCR-F) and on the attachment protein gene (nRT-PCR-G) of the BRSV, to be used for viral detection in infected cells. The primers were selected from two essential genes ( $F$ and $G$ ) of the BRSV genome because both are enveloped by highly immunogenic proteins. The $\mathrm{G}$ protein is the most antigenically dissimilar protein among the BRSV strains (19), and for this reason is extensively used in comparative BRSV studies.

The viral RNA was used as a template for cDNA synthesis with extension from a synthetic oligonucleotide primer. All bovine strains tested, BRSV-25-BR, BRSV-88 and Lehmkuhl 375, were detected by the nRTPCR-F and nRT-PCR-G assays. An nRT- 
PCR product of the expected size, $481 \mathrm{bp}$ corresponding to part of the $\mathrm{F}$ gene and 371 bp corresponding to part of the $G$ gene, was observed (Figure 2). Amplification products were not observed for the negative control. The same regions were amplified in the Brazilian sample to confirm that the isolated virus was BRSV.

The optimal RT-PCR conditions were different for nRT-PCR-G and nRT-PCR-F and also differed between the first and the second RT-PCR-F. These conditions were adjusted in order to minimize nonspecifically amplified bands.

The results obtained in this study indicate that it is possible to use this technique for a fast detection of BRSV; this advance is indeed of great clinical importance, producing rapid results, in contrast to virus culture. The use of nRT-PCR with inner primers allowed us to enhance the sensitivity and specificity of the test. Because of its fast execution, sensitivity and specificity, nRTPCR could be a useful tool for the diagnosis of clinical samples.

Nested RT-PCR-G seems to be a good option for routine disease diagnosis and for
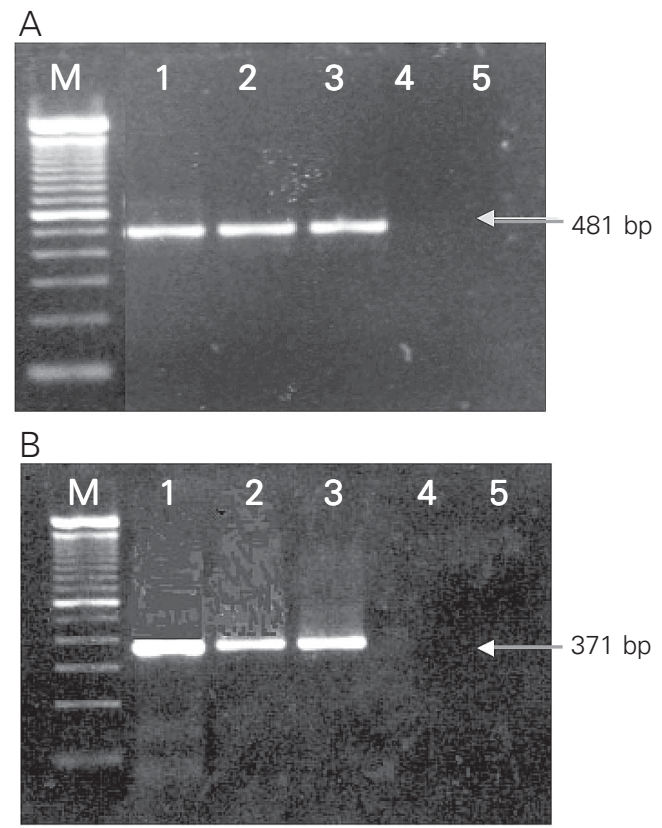

analysis of the diversity of the BRSV genome. The extensive application of the nRTPCR-G technique in the future will provide information on BRSV genotypes circulating in Brazil and may contribute to the establishment of official control programs against this virus.
Figure 2. Amplified products from viral samples proliferated in cell culture. Nested RT-PCR-F (A) and nested RT-PCR-G (B). Lanes 1, 2 and 3 represent BRSV-25-BR, BRSV-88 and Lehmkuhl 375 reaction products, respectively. Lane 4 represents SHS-121-BR, lane 5 is the blank, and $\mathrm{M}$ denotes the 100-bp DNA ladder lane.

\section{References}

1. Paccaud MF \& Jacquier C (1970). A respiratory syncytial virus of bovine origin. Archiv für die Gesamte Virusforschung, 30: 327-342.

2. Buchholz UJ, Finke S \& Conzelmann KK (1999). Generation of bovine respiratory syncytial virus (BRSV) from cDNA: BRSV NS2 is not essential for virus replication in tissue culture, and the human RSV leader region acts as a functional BRSV genome promoter. Journal of Virology, 73: 251-259.

3. Pastey MK \& Samal SK (1995). Nucleotide sequence analysis of the non-structural NS1 (1C) and NS2 (1B) protein genes of bovine respiratory syncytial virus. Journal of General Virology, 76: 193-197.

4. Furze JM, Roberts SR, Wertz GW \& Taylor G (1997). Antigenically distinct $\mathrm{G}$ glycoproteins of BRSV strains share a high degree of genetic homogeneity. Virology, 231: 48-58.

5. Vilcek S, Elvander M, Ballagi-Pordany A \& Belak S (1994). Development of nested PCR assays for detection of bovine respiratory syncytial virus in clinical samples. Journal of Clinical Microbiology, 32: 2225-2231.

6. Gonçalves IPD, Jost HC, Soglio AD, Simanke AT, Hotzel I \& Moojen $V$ (1993). Detection of bovine respiratory syncytial virus in calves of Rio Grande do Sul, Brazil. Ciência Rural, Santa Maria, 23: 389-390.

7. Campalans J \& Arns CW (1997). Serological evidence of bovine respiratory syncytial virus in Brazil. Virus Reviews and Research, 1-2:
$50-56$

8. Driemeier D, Gomes MJP, Moojen V, Arns CW, Vogg G, Kessler L \& Da Costa UM (1997). Manifestação clínico-patológica de infecção natural pelo vírus respiratório sincicial bovino (BRSV) em bovinos de criação extensiva no Rio Grande do Sul, Brasil. Pesquisa Veterinária Brasileira, 17: 77-81.

9. Flores EF, Weiblen R, Medeiros M, Botton SA, Irigoyen LF, Driemeier D, Schuch LF \& Moraes M (2000). A retrospective search for bovine respiratory syncytial virus (BRSV) antigens in histological specimens by immunofluorescence and immunohistochemistry. Pesquisa Veterinária Brasileira, 20: 139-143.

10. Dubovi EJ (1993). Diagnosing BRSV infection: A laboratory perspective. Veterinary Medicine, 88: 888-893.

11. West K, Bodgan J, Hamel A, Nayar G, Morley PS, Haines DM \& Ellis JA (1998). A comparison of diagnostic methods for the detection of bovine respiratory syncytial virus in experimental clinical specimens. Canadian Journal of Veterinary Research, 62: 245-250.

12. von Mayr A, Bachmann PA, Bibrack B \& Wittmann G (1974). Züchtung von Viren in Zellkulturen. In: Virologische Arbeitsmethoden. Band I. Gustav Fischer Verlag, Stuttgart, Germany, 231-262.

13. Gough RE \& Collins MS (1989). Antigenic relationships of three turkey rhinotracheitis viruses. Avian Pathology, 18: 227-238. 
14. Barth OM (1984). Estudos sobre a contrastação negativa de suspensões virais. Revista Brasileira de Biologia, 44: 71-80.

15. Stott EJ \& Taylor G (1985). Respiratory syncytial virus. Brief Review. Archives of Virology, 84: 1-52.

16. Mallipeddi SK, Samal SK \& Mohanty SB (1990). Analysis of polypeptides synthesized in bovine respiratory syncytial virus infected cells. Archives of Virology, 115: 23-36.

17. Paton AW, Paton JC, Lawrence AJ, Goldwater PN \& Harris RJ (1992). Rapid detection of Respiratory Syncytial Virus in nasopharyngeal aspirates by reverse transcription and polymerase chain reac- tion amplification. Journal of Clinical Microbiology, 30: 901-904.

18. Valarcher JF, Bourhy H, Gelfi J \& Schelcher F (1999). Evaluation of a nested reverse transcription-PCR assay based on the nucleoprotein gene for diagnosis of spontaneous and experimental bovine respiratory syncytial virus infections. Journal of Clinical Microbiology, 37: 1858-1862.

19. Prozzi D, Walravens K, Langedijk JPM, Kramps JA \& Letesson JJ (1997). Antigenic and molecular analyses of the variability of bovine respiratory syncytial virus G glycoprotein. Journal of General Virology, 78: 359-366. 